\title{
Stress induced cardiomyopathy presenting as acute coronary syndrome: Tako-Tsubo in Mercogliano, Southern Italy F Cangella1 ${ }^{1}$, A Medolla ${ }^{1}$, G De Fazio ${ }^{1}$, C Iuliano ${ }^{1}$, N Curcio ${ }^{1}$, L Salemme ${ }^{1}$, G Mottola ${ }^{1}$ and Marco Agrusta*1,2
}

Address: ${ }^{1}$ Cardiology Department, 'Montevergine' Cardilogy Clinic, Mercogliano, Italy and ${ }^{2}$ Casa di Cura Montevergine, Via Mario Malzoni, 1 , 83013 Mercogliano (Av.), Italy

Email: F Cangella - f.cangella@libero.it; A Medolla - angiomed@virgilio.it; G De Fazio - scientific@clinicamontevergine.it;

C Iuliano - tina.iuliano@tin.it; N Curcio - nunziocurcio@libero.it; L Salemme - luigisalemme@tiscali.it;

G Mottola - gaetano_mottola@virgilio.it; Marco Agrusta* - scientific@clinicamontevergine.it

* Corresponding author

Published: 16 October 2007

Cardiovascular Ultrasound 2007, 5:36 doi:10.1 | 86/1476-7|20-5-36
Received: 6 June 2007

Accepted: 16 October 2007

This article is available from: http://www.cardiovascularultrasound.com/content/5/I/36

(C) 2007 Cangella et al; licensee BioMed Central Ltd.

This is an Open Access article distributed under the terms of the Creative Commons Attribution License (http://creativecommons.org/licenses/by/2.0), which permits unrestricted use, distribution, and reproduction in any medium, provided the original work is properly cited.

\begin{abstract}
Background: Tako-tsubo syndrome (TTS) in its typical (apical) and atypical (non-apical) forms is being increasingly recognized in the West owing to early systematic coronary angiography in acute coronary syndromes (ACS).
\end{abstract}

Aim of the study: To assess the incidence, the clinical characteristics and the outcome of TTS in a single high volume cath lab in Southern Italy over the last 6 years.

Methods: Among 1674 consecutive patients (pts) referred to our coronary care units in the last 6 years (200I-2006) for ACS we selected $6(0.5 \%)$ pts (6 women; age $57 \pm 6$ years) who fulfilled the following 4 criteria: I) transient left ventricular wall motion abnormalities resulting in ballooning at contrast ventricolographic or echocardiographic evaluation; 2) normal coronary artery on coronary angiography performed $5 \pm 9$ hours from hospitalization; 3) new electrocardiographic ischemic-like abnormalities (either ST-segment elevation or T-wave inversion) and 4) emotional or physical trigger event.

Results: At admission all pts had presumptive diagnosis of ACS and ECG revealed ST elevation in $3(50 \%)$ and T wave inversion with QT elongation in $3(50 \%)$. In the acute phase cardiogenic shock occurred in $2(33 \%)$ and heart failure in $1(16 \%)$. Presenting symptoms were chest pain in $6(100 \%)$, dyspnoea in 2 (33\%) and lipotimia in I (16\%). At echocardiographic-ventricolographic assessment, the mechanical dysfunction (ballooning) was apical in all 6 pts ("classic" TTS). In all patients wall motion abnormalities completely reversed within $4.5 \pm 1.5$ days. The region of initial recovery was the anterior and lateral wall in 4 cases and the lateral wall in 2 cases. Ejection fraction was $35 \pm 8 \%$ in the acute phase and increased progressively at discharge $(55 \pm 6 \%)$ and at $4 \mathrm{I} \pm 20$ months followup $(60 \pm 4 \%, p<0.00$ I vs. baseline). All patients remained asymptomatic with minimal (aspirin, beta blockers, antihypertensive and antidislipidemic therapy) treatment.

Conclusion: Classic TTS is a frequent serendipitous diagnosis after coronary angiography showed "surprisingly" normal findings in a clinical setting mimicking an ACS. Despite its long-term good prognosis life threatening complications in the acute phase can occur. 


\section{Introduction}

Stress induced cardiomyopathy is described as an acute cardiomyopathy characterized by acute, but rapidly reversible, left ventricle systolic dysfunction in the absence of atherosclerotic coronary artery disease which appears to be triggered by intense psychological and physical stress [1]. This syndrome has been firstly described in Japan in 1990 by Sato et al, who proposed the term 'TakoTsubo', the name used by Japanese fishermen for the fishing pot with a narrow neck and a wide base that is used to trap octopus. In fact, the left ventricle with Tako-tsubo cardiomyopathy shows the peculiar appearance of a rounded bottom an a narrow neck on the end-systolic left ventriculogram [2]. Various definitions have been proposed in order to describe this syndrome such as apical ballooning syndrome (ABS), broken heart syndrome and stress or ampulla cardiomyopathy [2]. The exact incidence of ABS appears to be unclear, it ranges form 1 to $2 \%$ of patients who present, at admission, a clinical scenario which often mimics acute myocardial infarction. The occurrence of ABS syndrome seems to be significantly recurrent in postmenopausal women although it has been described also in younger women and males. The most frequent finding on the admission ECG is a mild ST-segment elevation which appears to occur in approximately $50-60 \%$ of the patients [2]. The 12-lead ECG alone in not helpful in differentiating ABS from ST-elevation myocardial infarction.

Characteristic evolutionary changes that occur over 2 to 3 days include resolution of the ST-segment elevation and subsequent development of diffuse and often deep Twave inversion that involves most leads. New pathological Q waves may occasionally be observed and, furthermore, it has been possible to observe a prolongation of the corrected QT interval [2]. Although there are rare exceptions, the proposed Echocardiographic Mayo Clinic Criteria for the clinical diagnosis of ABS underline a transient apical regional wall motion abnormalities, usually extending beyond a single epicardial vascular distribution. Most, if not all of the patients, appear to have a mild increase of cardiac biomarkers. Typically, no obstructive coronary artery disease has been found. Although the pathogenesis still remains unclear, a common element appears to be an exaggerated sympathetic activation. The mechanism underlying the association between sympathetic stimulation and myocardial stunning in unknown. One possibility is ischemia resulting from epicardial coronary arterial spasm. An alternative mechanism is microvascular spasm. A third possible mechanism is direct myocyte injury [3]. Activation of cardiac adrenoreceptors is experimentally proven to induce left ventricular (apical) dysfunction. In fact, there is evidence that apical myocardium has enhanced responsiveness to symphatetic stimulation [4], potentially making the apex more vulnerable to sudden surges in circulating catecholamine levels. Aim of the present study was to describe a case series of 6 ABS observed in the last 6 years in a tertiary care referral center with high volume cardiac cath lab in Mercogliano, Southern Italy.

\section{Methods}

During the last 6 years (2001-2006), among 1674 consecutive patients (pts) referred to our coronary care units for ACS, 6 patients (age $57 \pm 6$ years; all women) presenting at admission with acute onset of cardiovascular event have been retrospectively selected. All fulfilledthe following 4 predetermined criteria to define Tako-Tsubo cardiomyopathy [2]: 1) transientleft ventricularwall motion abnormalities resulting in ballooning at contrast ventricolographic or echocardiographic evaluation; 2) normal coronary artery on coronary angiography (performed $5 \pm$ 9 hours from the hospitalization); 3) new electrocardiographic ischemic-like abnormalities (either ST-segment elevation or T-wave inversion) and 4) emotional or physical trigger event.

All patients underwent, at admission, two-dimensional transthoracic echocardiography, 12 lead electrocardiogram, serial measurements of cardiac isoenzymes including creatine kinase, creatine kinase $\mathrm{MB}$ fraction, and troponin. Transthoracic echocardiography has again been repeated at discharge. All patients have been followed-up for a median period of 40 months.

\section{Echocardiographic data}

All patients underwent comprehensive transthoracic echocardiography examination at rest, upon discharge and at a median period of 40 months follow-up. Endsystolic, end-diastolic volumes, ejection fraction and wall motion score index (each segment scored from $1=$ nor$\mathrm{mal} /$ hyperkinetic, to $4=$ dyskinetic, in a 16 segment model of the left ventricle) were calculated following the recommendations of the American Society of Echocardiography [5]. The left ventricular volumes and ejection fraction were measured by modified biplane Simpson's method and adjusted for body surface area. The systolic pulmonary artery pressure has been derived from maximal velocity of tricuspid Doppler tracing adding the value of the right atrial pressure. The right atrial pressure was estimated on the basis of inspiratory collapse index of the inferior vena cava. Diastolic function was determined from the pattern of mitral and pulmonary venous flow velocity by pulsed Doppler echocardiography, complemented by mitral annular velocity by tissue Doppler imaging, when needed [5]. Diastolic dysfunction was staged as being "absent" (grade 0), "mild" (grade 1, impaired relaxation), "moderate" (grade 2, pseudo-normalized filling pattern), and "severe" (grade 3, restrictive filling pattern). All echocardiographic examinations were performed using commercially available instruments with 
a cardiac probe (2.5-3.5 MHz): Acuson Sequoia (Mountain View, Ca), Esaote Mylab (Genoa, Italy).

\section{Statistical analysis}

Values are expressed as mean \pm standard deviation (SD) unless indicated otherwise. Groups were compared by parametric or non-parametric tests (t-tests and WilcoxonMann-Whitney tests, respectively). More than 2 groups were compared using the analysis of variance. Post-hoc tests were performed (if significant differences were proved globally) with the help of Newman-Keuls test. A p $<0.05$ was considered as statistically significant.

\section{Results}

Demographic and clinical features of the study patients are reported in Table 1 . All patients reported a physical and/or an emotional distress in the hours immediately before admission consisting of death of a relative in 4, strong financial loss in 1 and heated argument with daughter in 1 . The presenting symptoms were chest pain in 6, dyspnea in 2, lipotimia in 1 and severe dyspnea with acute heart failure in 1 patient. The initial electrocardiogram showed sinus rhythm in all patients with ABS, with a median heart rate of 105 beats per minute; 3 patients had ST-segment elevation of at least $1 \mathrm{~mm}$, and 3 patients had diffuse T-wave inversion; 3 patients had a prolonged QT interval corrected for heart rate (QTc). Q waves did not appear in any of the observed patients. On admission, echocardiogram showed an apical dysfunction in all of the patients. Over time, there was a normalization of regional wall motion (Figure 1 ), a reduction of left ven-
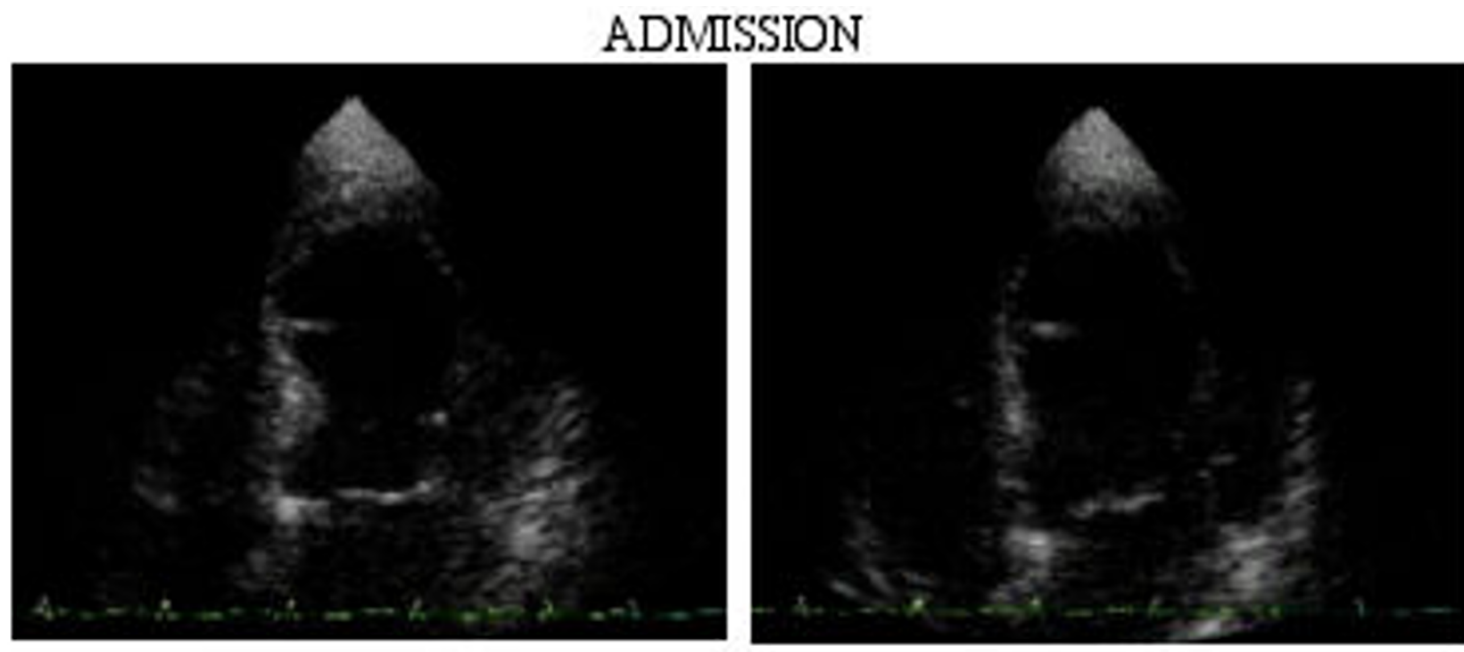

\section{End-Diastolic}

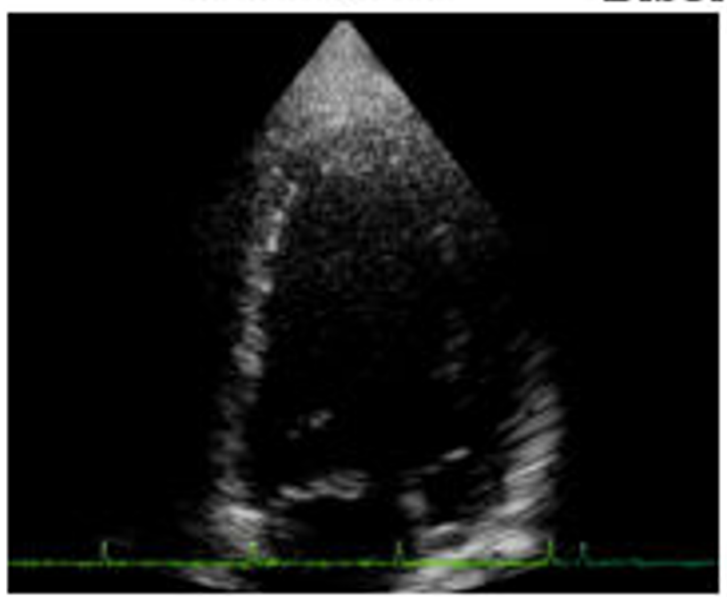

End-systolic

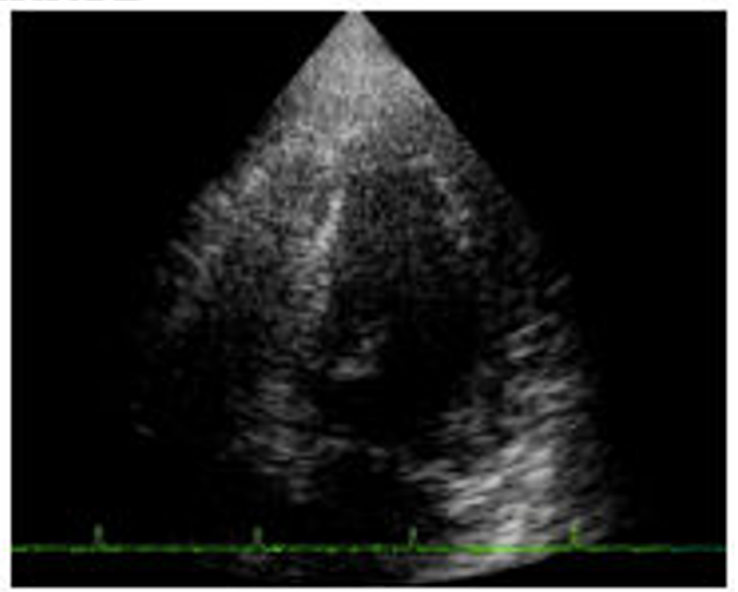

Figure I

A typical echocardiographic appearance of apical ballooning syndrome. Left up: end-diastolic image on admission and left down end-diastolic image at discharge; right up: end-systolic image on admission and right down: end-systolic image at discharge. 
Table I: Clinical and Electrocardiographic features

\begin{tabular}{lc}
\hline Age (years) & $57 \pm 6$ \\
Sex (Male/Female) & $0 / 6$ \\
Smoking habit, $\mathrm{n}(\%)$ & 0 \\
Hypercholesterolemia, $\mathrm{n}(\%)$ & $2(33.3 \%)$ \\
Hypertension, $\mathrm{n}(\%)$ & $3(50 \%)$ \\
Diabetes mellitus, $\mathrm{n}(\%)$ & $1(16.6 \%)$ \\
Chest pain/Dyspnea & $6 / 2$ \\
Menopause, $\mathrm{n}(\%)$ & $5(83.3 \%)$ \\
CK (U/l) & $196.2 \pm 91$ \\
CK-MB (U/L) & $19.5 \pm 5.6$ \\
CK normalization (days) & $2.6 \pm 1.2$ \\
Troponin (ng/ml) & $14.5 \pm 1.2$ \\
Mioglobin (ng/ml) & $78.6 \pm 36.2$ \\
White blood cells/ $\mu \mathrm{l}$ & $11866 \pm 4500$ \\
ESR & $26.8 \pm 16$ \\
C-reactive protein & $20.3 \pm 13.4$ \\
Heart Rate (beats/min) & $110 \pm 13$ \\
ST - elevation & $3(50 \%)$ \\
T-wave inversion & $3(50 \%)$ \\
ST/T modification Peripheral leads & $3(50 \%)$ \\
ST/T modification Precordial leads & $6(100 \%)$ \\
Long QT & $3(50 \%)$ \\
Q wave & 0 \\
\hline
\end{tabular}

tricular end-systolic volume and improvement of diastolic function (Table 2).

Emergency coronary angiography showed angiographically normal coronary arteries in all with ventriculographic confirmation of apical ballooning observed by echocardiogram (Figure 2). Due to acute refractory heart failure, intraortic balloon pump was used in 2 patients. At ventriculography all of the patients showed apical akinesis and normokinesis of middle and basal segments. All patients were uneventfully discharged and remained asymptomatic at follow - up (median 44, range 12-68 months). At follow-up echocardiogram, normal regional and global left ventricular systolic and diastolic function were restored (Table 2).

\section{Discussion}

We described 6 cases of tako-tsubo cardiomyopathy in a region of Southern Italy close to Naples. In the contemporary definition and classification of the Cardiomyopathies proposed in 2006 by the American Heart Association, stress ("Tako-Tsubo") cardiomyopathy is classified among acquired forms of cardiomyopathy [6]. A recent systematic review on apical ballooning syndrome identified 14 case series published on international peerreviewed literature, totalling about 200 patients [7]. Our data are broadly consistent with these previous reports, regarding epidemiological profile, clinical presentation and long-term follow-up. ABS accounts $2 \%$ of acute coronary syndromes, with most cases occurring in post-menopausal women. Ischemic-like ST-T changes most frequently occur with mild elevation of cardiac biomarkers. The acute left ventricular dysfunction typically involves the apex, although recently some apex-sparing variants of the syndrome have been described [8]. The acute left ventricular dysfunction usually recovers in a few days or weeks, and long-term follow-up is usually uneventful. Of note, the geographic origin of published reports originates from Japan (9 studies), USA (3 studies), Belgium and Spain (1 study each) [9]. In the present case series, we describe 6 cases all originating from Irpinia, a region of Southern Italy, near Naples but with different ethnic origin and lifestyles (Figure 3). This report again emphasizes that ABS can be much more diffuse than previously thought, and it can be easily recognized, if one thinks of it and applies clearly pre-defined criteria.

Clinicians should consider this syndrome in the differential diagnosis of acute coronary syndromes, especially in post-menopausal women with a recent history of acute emotional or physical stress. The non-invasive suspicion rests on the typical echocardiographic appearance apical ballooning - usually reversible within a few days or weeks. The angiographic documentation of normal coronary arteries is necessary to substantiate the diagnosis.

\section{List of Abbreviations}

ABS: Apical ballooning syndrome

ACS: Acute coronary syndrome

Pt: patient

Table 2: Echocardiographic findings

\begin{tabular}{|c|c|c|c|}
\hline & On admission & Pre-discharge & Follow-up \\
\hline $\mathrm{EDV} \mathrm{mL}$ & $|44| \pm 46.6$. & $116.6 \pm 45.8^{*}$ & $96.8 \pm 36.9 *$ \\
\hline ESV mL & $92.8 \pm 36.3$ & $52.7 \pm 21.1^{*}$ & $36.6 \pm \mid 4 . I^{*}$ \\
\hline $\mathrm{EF}(\%)$ & $35 \pm 8$ & $55 \pm 6^{*}$ & $60 \pm 4^{*}$ \\
\hline WMSI & $1.7 \pm 0.1$ & $1 \pm 0 * *$ & $1 \pm 0 * *$ \\
\hline Diastolic dysfunction $\geq$ moderate $\mathrm{n}(\%)$ & $3(50 \%)$ & $0 * *$ & $0^{*}$ \\
\hline PAPS $(\mathrm{mmH})$ & $30.6 \pm 3.8$ & $28.7 \pm 2$ & $27.3 \pm 2.2$ \\
\hline
\end{tabular}

EDV = end-diastolic volume; ESV = end-systolic volume; PAPS = Pulmonary artery arterial pressure; WMSI = Wall Motion Score Index

$* \mathrm{p}<.05$ vs. baseline; ${ }^{* *} \mathrm{p}<0.01$ vs. baseline 


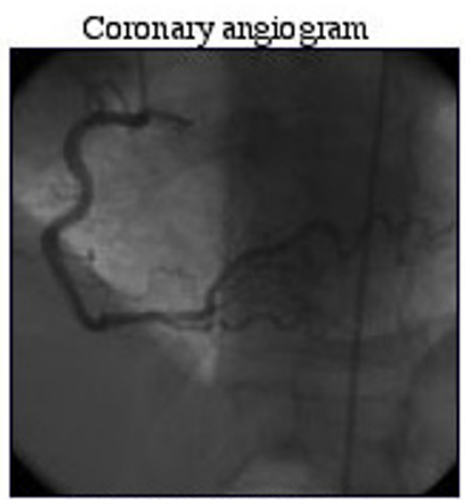

Right coronary artery

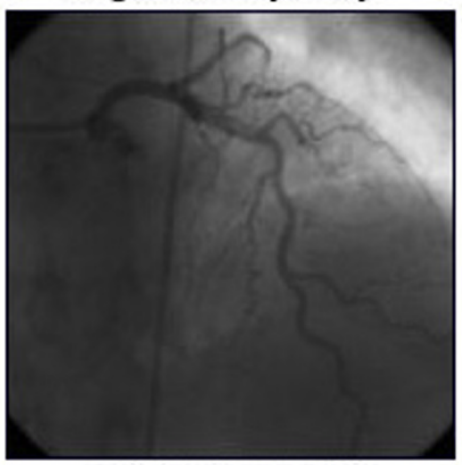

Left coronary artery

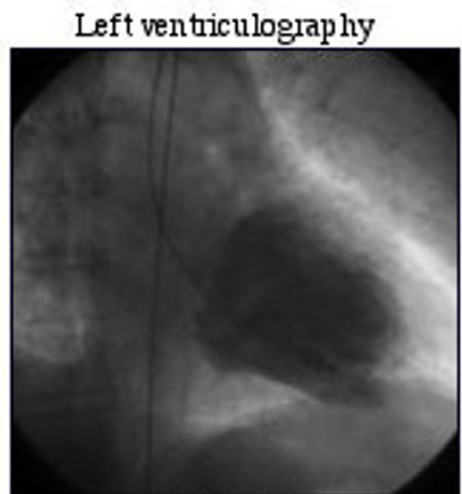

End-diastole

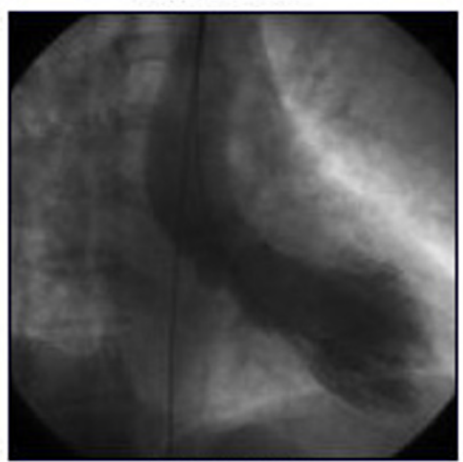

End-systole

Figure 2

A typical angiographic appearance of apical ballooning syndrome with normal coronary arteries.

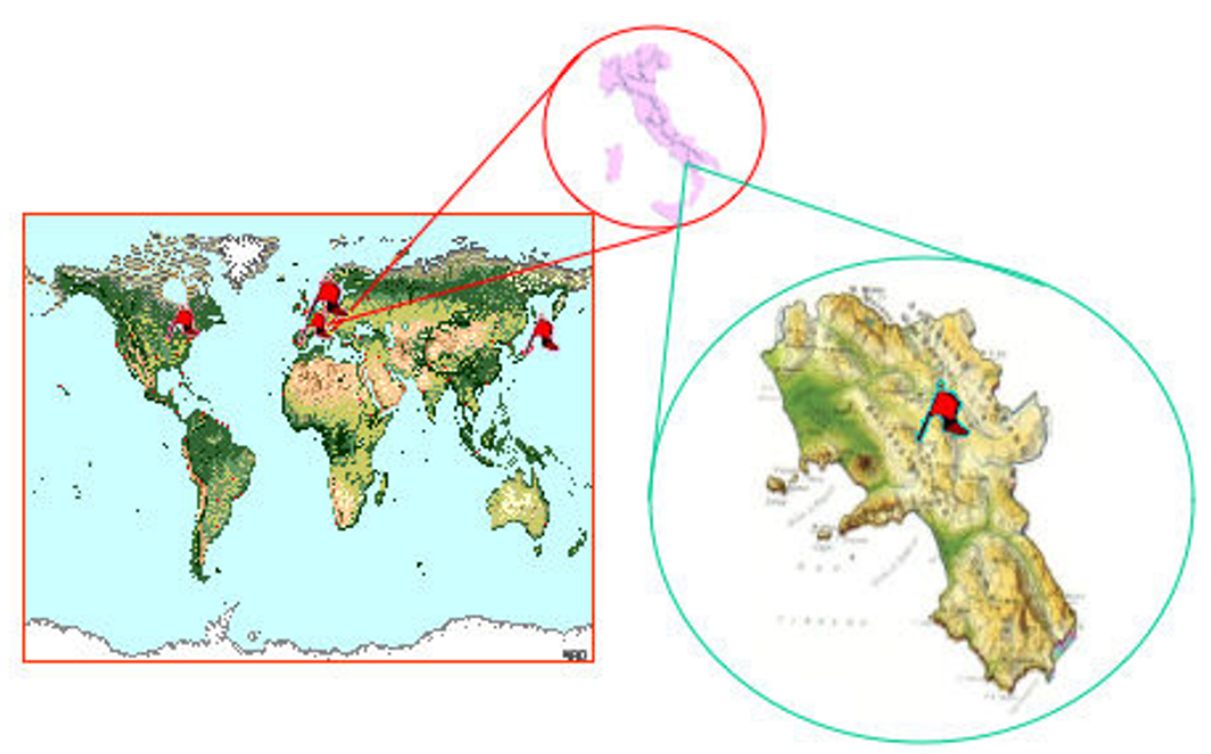

\section{Figure 3}

Geographic origin of published reports and spotlight on Tako-Tsubo in Mercogliano, Southern Italy. 
TTS: Tako-tsubo syndrome

\section{References}

I. Sharkey SW, Lesser JR, Zenovich AG, Maron MS, Lindberg J, Longe FT, Maron BJ: Acute and Reversible Cardiomyopathy Provoked by Stress in Women from the United States. Circulation 2005, I I I:472-479.

2. Prasad A: Apical ballooning syndrome: an important differential diagnosis of acute myocardial infarction. Circulation 2007, I I 5(5):e56-e59.

3. Wittstein IS, Thiemann DR, Lima JAC, Baughman KL, Schulman SP, Gerstenblith G, Wu KC, Rade JJ, Bivalacqua TJ, Champion C: Neurohumoral features of Myocardial Stunning due to Sudden Emotional Stress. N Engl J Med 2005, 352(6):539-48.

4. Mori H, Ishikawa S, Kojima S, Hayashi J, Watanabe Y, Hoffman Jl, Okino $\mathrm{H}$, et al.: Increased responsiveness of left ventricular apical myocardium to adrenergic stimuli. Cardiovasc Res 1993, 27(2): 192-198.

5. Quinones MA, Otto CM, Stoddard M, Waggoner A, Zoghbi WA: Doppler Quantification Task Force of the Nomenclature and Standards Committee of the American Society of Echocardiography. J Am Soc Echocardiogr 2002, I 5(2): 167-84.

6. Maron BJ, Towbin A, Thiene G, Antzelevitch C, Corrado D, Arnett D, Moss JA, Seidman E, Young JB: Contemporary definitions and classification of the cardiomyopathies: an American Heart Association Scientific Statement from the Council on Clinical Cardiology, Heart Failure and Transplantation Committee; Quality of Care and Outcomes Research and Functional Genomics and Translational Biology Interdisciplinary Working Groups; and Council on Epidemiology and Prevention. Circulation I I3( I4): I807-I6. 2006; Apr II

7. Gianni M, Dentali F, Grandi AM, Sumner G, Hiralal R, Lonn E: Apical ballooning syndrome or takotsubo cardiomyopathy: a systematic review. Eur Heart J 2006, 27( I 3): I523-I529.

8. Hurst RT, Askew JW, Reuss CS, Lee RW, Sweeney JP, Fortuin FD, Oh JK, Tajik AJ: Transient midventricular ballooning syndrome: a new variant. J Am Coll Cardiol 2006, 48:579-583.

9. Dec WG: Recognition of the Apical Ballooning Syndrome in the United States. Circulation 2005, I I I:388-390.

Publish with Biomed Central and every scientist can read your work free of charge

"BioMed Central will be the most significant development for disseminating the results of biomedical research in our lifetime. "

Sir Paul Nurse, Cancer Research UK

Your research papers will be:

- available free of charge to the entire biomedical community

- peer reviewed and published immediately upon acceptance

- cited in PubMed and archived on PubMed Central

- yours - you keep the copyright
BiolMedcentral 